\title{
Depression Does Not Affect the Treatment Outcome of CBT for Panic and Agoraphobia: Results from a Multicenter Randomized Trial
}

\author{
Angela Emmrich ${ }^{a}$ Katja Beesdo-Baum ${ }^{a} \quad$ Andrew T. Gloster ${ }^{a} \quad$ Susanne Knappe ${ }^{a}$ \\ Michael Höfler ${ }^{a}$ Volker Arolt ${ }^{b} \quad$ Jürgen Deckert ${ }^{d} \quad$ Alexander L. Gerlach ${ }^{c, e}$ \\ Alfons Hamm ${ }^{f}$ Tilo Kircherg Thomas Lang ${ }^{a, h} \quad$ Jan Richter $^{f} \quad$ Andreas Ströhle $^{\mathrm{i}}$ \\ Peter Zwanzger ${ }^{\mathrm{b}}$ Hans-Ulrich Wittchen ${ }^{\mathrm{a}}$ \\ anstitute of Clinical Psychology and Psychotherapy, Technische Universität Dresden, Dresden; ${ }^{\mathrm{b}}$ Department of \\ Psychiatry and ${ }^{C}$ Institute of Clinical Psychology and Psychological Assessment, University of Münster, Münster; \\ ${ }^{\mathrm{d}}$ Department of Psychiatry, University of Würzburg, Würzburg; ${ }^{\mathrm{e}}$ Department of Psychology, University of \\ Cologne, Cologne; ${ }^{\mathrm{D}}$ Department of Biological and Clinical Psychology, Ernst-Moritz-Arndt University, Greifswald;

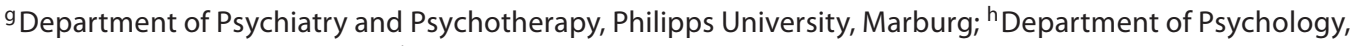 \\ University of Bremen, Bremen; 'Department of Psychiatry and Psychotherapy, Campus Charité Mitte, Charité \\ Universitätsmedizin Berlin, Berlin, Germany
}

\section{Key Words}

Panic disorder • Agoraphobia • Depression • Comorbidity • Cognitive-behavioral therapy • Exposure $\cdot$ Randomized controlled trial

\begin{abstract}
Background: Controversy surrounds the questions whether co-occurring depression has negative effects on cognitivebehavioral therapy (CBT) outcomes in patients with panic disorder (PD) and agoraphobia (AG) and whether treatment for PD and AG (PD/AG) also reduces depressive symptomatology. Methods: Post-hoc analyses of randomized clinical trial data of 369 outpatients with primary PD/AG (DSM-IV-TR criteria) treated with a 12-session manualized CBT $(n=301)$ and a waitlist control group $(n=68)$. Patients with comorbid depression (DSM-IV-TR major depression, dysthymia, or both: $43.2 \%$ CBT, $42.7 \%$ controls) were compared to patients without depression regarding anxiety and depression out-
\end{abstract}

comes (Clinical Global Impression Scale [CGI], Hamilton Anxiety Rating Scale [HAM-A], number of panic attacks, Mobility Inventory [MI], Panic and Agoraphobia Scale, Beck Depression Inventory) at post-treatment and follow-up (categorical). Further, the role of severity of depressive symptoms on anxiety/depression outcome measures was examined (dimensional). Results: Comorbid depression did not have a significant overall effect on anxiety outcomes at post-treatment and follow-up, except for slightly diminished post-treatment effect sizes for clinician-rated CGI $(p=0.03)$ and HAM-A ( $p=$ 0.008 ) when adjusting for baseline anxiety severity. In the dimensional model, higher baseline depression scores were associated with lower effect sizes at post-treatment (except for MI), but not at follow-up (except for HAM-A). Depressive symptoms improved irrespective of the presence of depression. Conclusions: Exposure-based CBT for primary PD/AG effectively reduces anxiety and depressive symptoms, irrespective of comorbid depression or depressive symptomatology.

\section{KARGER}

Fax +4161306 1234

E-Mail karger@karger.ch

www.karger.com (c) 2012 S. Karger AG, Basel

$0033-3190 / 12 / 0813-0161 \$ 38.00 / 0$

Accessible online at:

www.karger.com/pps
Hans-Ulrich Wittchen

Technische Universität Dresden, Institute of Clinical Psychology and Psychotherapy Chemnitzer Strasse 46

DE-01187 Dresden (Germany)

Tel. +49351 4633 6983, E-Mail wittchen@psychologie.tu-dresden.de 


\section{Introduction}

Cognitive-behavioral therapy (CBT) specifically targeting anxiety-related cognitions and behavior is efficacious for panic disorder (PD) with and without agoraphobia (AG) [1-3] and considered as a first-line treatment $[4,5]$. There is controversy, however, regarding the question of whether (1) comorbid depression negatively affects CBT outcomes in patients with PD and AG (PD/ $A G$ ), and (2) CBT specifically designed for PD/AG also effectively reduces depressive symptomatology. These questions are important for clinical care given the epidemiological evidence that anxiety disorders are risk factors for depression and typically precede the onset of depression [6-13], and that depression is a frequent comorbid complication of PD/AG patients [14-19]. Comorbid depression in $\mathrm{PD} / \mathrm{AG}$ is associated with increased disability [15], higher overall illness severity [20-22] and more severe panic-related symptoms [23]. The question to what degree comorbid depression and severity of depression affects treatment response and long-term outcome is understudied, in part because randomized studies often exclude PD/AG with concurrent depression.

The few available studies reveal contradictory findings. Early studies suggested that comorbid depression does not negatively impact CBT for PD with or without AG [24, 25]. Similarly, naturalistic studies [22, 26-28], CBT studies $[21,23,29,30]$ and pharmacological studies $[31,32]$ did not find significant effects of comorbid depression on treatment response or long-term outcome. In contrast, poorer post-treatment outcomes for PD patients with and without AG suffering from comorbid depression were reported from some naturalistic [33-37], one CBT [38] and one pharmacotherapy study [39]. Furthermore, Brown et al. [40] (CBT) and Pollack et al. [41] (pharmacotherapy) reported that depression comorbidity was associated with poorer treatment response for PD, but not worse long-term outcome.

Most studies addressing these issues were underpowered to systematically test for possible effects of depression. The contradictory findings may also be due to differences in methodology such as diagnostic criteria, outcome measures, and exclusion criteria. Further, dimensional measures of depression have rarely been utilized. Two noteworthy exceptions are the studies of McLean et al. [21] who excluded patients with any current axis I disorder other than PD, AG or depression, and Keijsers et al. [42], who suggested that the initial level of depression predicted higher frequency of panic attacks and physical panic symptoms, but not agoraphobic avoidance behavior at the end of treatment.

The question of whether CBT for PD/AG effectively reduces depressive symptomatology is also a matter of debate. Tsao et al. $[30,43,44]$ suggested that CBT for PD/ AG significantly reduces overall comorbidity, including depression. However, their sample was small $(n=51)$ and the depression subgroup $(n=9)$ was insufficiently sized. A recent multicenter CBT trial for $\mathrm{PD}$ with or without AG by Allen et al. [23] observed reductions in depressive symptomatology without specifically targeting depressive conditions. Rates of major depressive disorder decreased, but the changes were nonsignificant. No significant reductions of depressive symptomatology were observed in the CBT treatment studies of McLean et al. [21] and Woody et al. [45]; however, they excluded patients with any comorbid axis I disorder other than PD, AG or depression.

Given these inconclusive findings, the current study examined: (1) whether comorbid depressive disorder (categorical) and the severity of depressive symptomatology (dimensional) are associated with poorer treatment response and long-term outcome of CBT for PD/AG as measured by clinician-rated anxiety scales (Hamilton Anxiety Rating Scale, Clinical Global Impression Scale) and self-reported anxiety measures (number of panic attacks, Mobility Inventory, Panic and Agoraphobia Scale), and (2) whether CBT for PD/AG also reduces the severity of co-occurring depressive symptoms without using explicit intervention components targeting depressive symptomatology.

\section{Methods}

Sample

Data were derived from a randomized clinical trial data of 369 $\mathrm{PD} / \mathrm{AG}$ patients treated with two state-of-the-art variants of CBT (with and without therapist-guided in situ exposure) for PD/AG $(\mathrm{n}=301)$ and a waitlist control group (WL; $\mathrm{n}=68)$ sampled from eight psychological and psychiatric outpatient study centers in Germany. Further study details are described elsewhere [3, 46, 47]. Individuals were eligible for original trial inclusion if they met DSM-IV-TR diagnostic criteria for PD/AG as the clinicianrated primary diagnosis, scored $\geq 18$ on the Hamilton Anxiety Scale, and $\geq 4$ on the Clinical Global Impression Scale. Exclusion criteria were noncompliance with the study schedule/requirements $(n=13)$, clinically significant suicidal intent $(n=0)$, meeting diagnostic criteria for any psychotic or bipolar disorder $(\mathrm{n}=$ $2)$, borderline personality disorder $(n=0)$, current alcohol dependence $(n=2)$, or having a medical condition that could explain the patient's symptoms $(n=4)$. Unlike other clinical randomized trials, other comorbid diagnoses were allowed. Patients had to 
agree to discontinue all psychopharmacological medication (including antidepressants and anxiolytics). Patients on psychopharmacological medication underwent a washout period prior to baseline.

For the present post-hoc analyses, all 369 patients with PD/AG were grouped into two categories: (1) with or (2) without comorbid depression (DSM-IV-TR major depressive episode and/or dysthymia). $43.2 \%(\mathrm{n}=130)$ of patients in the CBT treatment arms and $42.7 \%(\mathrm{n}=29)$ in the WL met criteria for MDE, dysthymia or both.

\section{Assessments}

Diagnoses were established face-to-face at baseline (BL) and 6-month follow-up (FU-6) using the computer-assisted version of the standardized Composite International Diagnostic Interview (CAPI-WHO-CIDI; DIAX-CIDI version) [48]. All diagnoses were subsequently verified by the clinical director of each site. Course and outcome assessments were conducted at BL, intermediate, post-treatment assessment and at FU-6. Primary outcome measures were the Hamilton Anxiety Scale (HAM-A; total score, somatic and psychic anxiety subscores) using the Structured Interview Guide $[49,50]$, the Clinical Global Impression Scale - Severity Subscale (CGI) [51], and patients self-report measures of the Panic and Agoraphobia Scale (PAS) [52], the number of panic attacks as reported in the PAS, and agoraphobic avoidance (Mobility Inventory [MI]) [53]. Depressive symptomatology was assessed by the Beck Depression Inventory, 2nd Edition (BDI-II, German version) [54].

\section{Treatment Conditions}

Treatment was based on a 12 -session manualized CBT treatment protocol, carried out over 6 weeks, and followed by two booster sessions $[3,46,55]$. CBT consisted of modules of psychoeducation, functional analysis of patients' symptoms and associated coping behaviors, rationale for exposure (i.e. sufficiently long and repeated exposure to feared stimuli without utilization of safety behaviors leads to fear reduction), interoceptive exposure, standardized in situ exposure (i.e. bus, shopping mall and forest), anticipatory anxiety, individualized in situ exposure (i.e. of the patients' most feared situations), and relapse prevention. The study compared two CBT variants (not examined in this paper), which differed exclusively with respect to the delivery, not in content, of the in situ exposure component. In situ exposures were either accompanied by the therapist $(\mathrm{T}+; \mathrm{n}=163)$ or thoroughly planned in the therapy room including mental rehearsal, anticipation of problems and with identical instructions not to use safety behaviors ( $\mathrm{T}-; \mathrm{n}=138$ ). In the $\mathrm{T}$ - variation, therapists did not leave the therapy room, but patients were instructed to engage in the in situ exposure exercises in the interval between the therapy sessions. Although there were some advantages for $\mathrm{T}+$, both treatment conditions were highly efficacious and efficient $[3,55,65]$. For the current analysis T+ and T- were collapsed together and are referred to as the CBT treatment group $(n=301)$.

\section{Statistical Analyses}

Effect sizes (ES) in therapy outcomes between study patients with and without comorbid depression were calculated as mean differences of outcome scores at post-treatment and FU-6, each divided by the pooled standard deviation at baseline (Cohen's d). This was the dependent variable of two sets of linear regression models: nonadjusting (model I) and adjusting for the baseline value of the respective outcome and the treatment condition (model II). Differences in binary outcomes were calculated with odds ratios (ORs) from logistic regressions.

The last observation carried forward (LOCF) method was applied in order to not lose observations due to dropout and to yield conservative outcome estimates. This should also lead to conservative estimates in differences in outcomes according to depression status at baseline (because the lack of difference at baseline achieved by adjusting for the baseline value of the outcome is carried forward). Statistical significance was considered at the 0.05 level. Completer ( $n=242$ at post-treatment; dropout rates were comparable for patients with [19.3\%] and without [20.0\%] comorbid depression) analyses were also conducted (available upon request).

The associations between dimensional depression severity (BDI-II) at BL and ES on outcome measures from BL to post-treatment or FU-6 were examined nonparametrically (local polynomial approximation [56]) for each outcome measure separately. Increasing/decreasing curves indicate lower/higher ES on the outcome measures with increasing BDI-II (fig. 1). To avoid overlapping points in the figures, some normally distributed noise (mean 0, SD 0.15-0.25) was added to the outcomes. This was not applied to the calculation of the fitted curves. We fitted (a) regressions with the linear predictor BDI-II at BL to assess overall associations, and (b) regressions with both the linear and the squared BDI-II to see whether deviations from linearity as suggested by some graphs were significant. Both models were repeated while adding the main effect term of depression at BL as well as the interaction term for depression $\times$ BDI-II and, on top of that, the interaction term for depression $\times$ squared BDI-II. To ease the language we use the term 'effect' to denote associations, but do not refer to causal relationships.

\section{Results}

\section{Characteristics Comparison Groups}

Patients with and without comorbid depression in both the CBT and the WL group were comparable with regard to psychosocial and clinical characteristics, with few exceptions (table 1). Rates of comorbid depression were also similar in the CBT and WL group. In the CBT group, $130 / 301$ (43.2\%) patients met criteria for a comorbid depressive disorder at BL (MDE alone $\mathrm{n}=80$ [26.6\%], dysthymia alone $\mathrm{n}=19$ [6.3\%], MDE and dysthymia $\mathrm{n}=$ $31[10.3 \%])$. In the WL 29/68 (42.7\%) of patients met criteria for comorbid depression (MDE alone $n=16$ [23.5\%], dysthymia alone $\mathrm{n}=5[7.4 \%], \mathrm{MDE}$ and dysthymia $\mathrm{n}=8$ [11.8\%]).

In the CBT group, PD/AG patients with comorbid depression were younger (table 1), had more frequently other comorbid conditions (most frequently specific phobia [71.1\%] and social phobia [41.9\%]), reported earlier onset of PD/AG and scored significantly higher on 


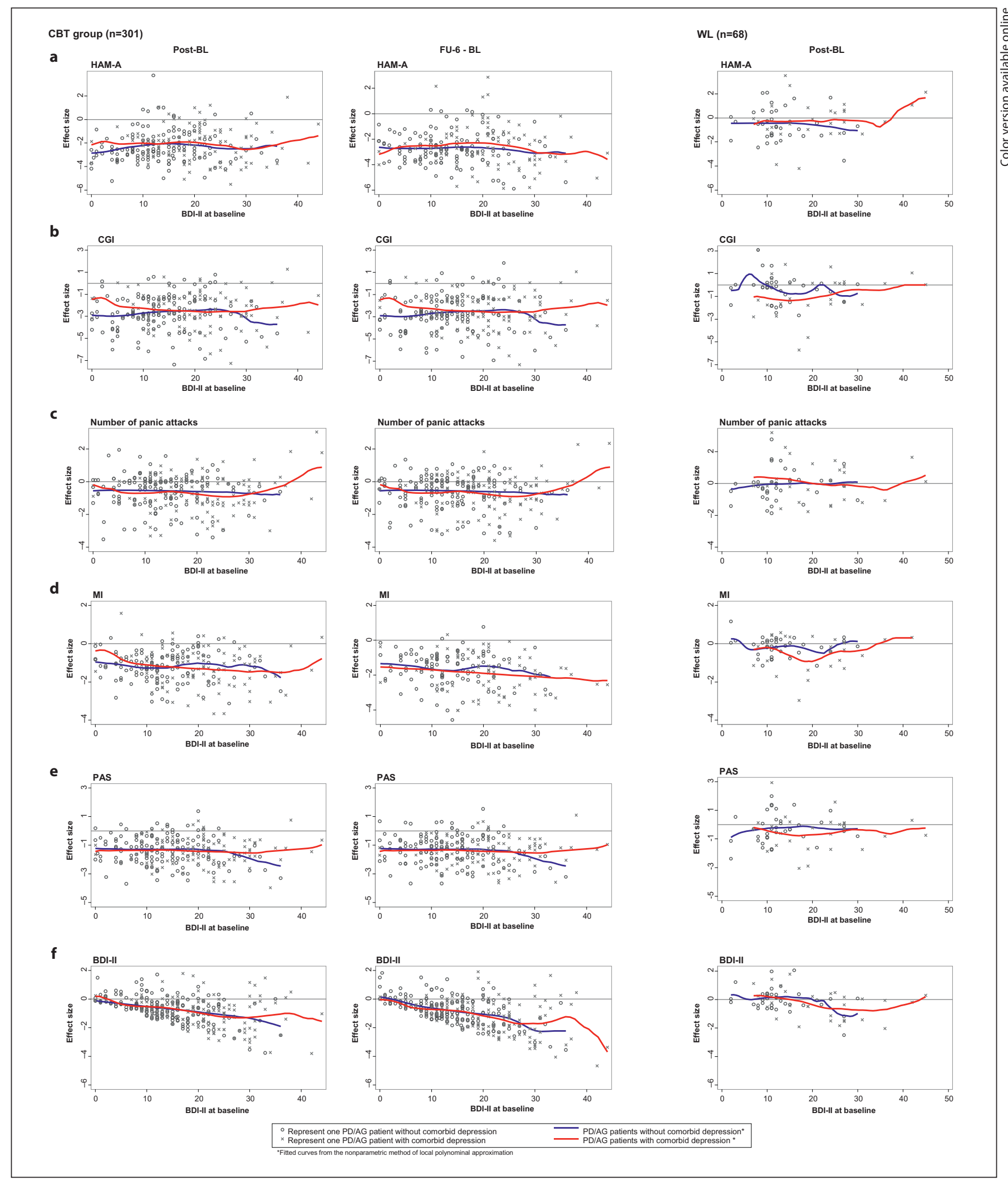

Fig. 1. Reductions in anxiety and depression outcome measures by baseline BDI-II for the CBT group at Post and FU-6 (left) and the WL at Post (right). 
Table 1. Comparison groups: baseline and clinical characteristics

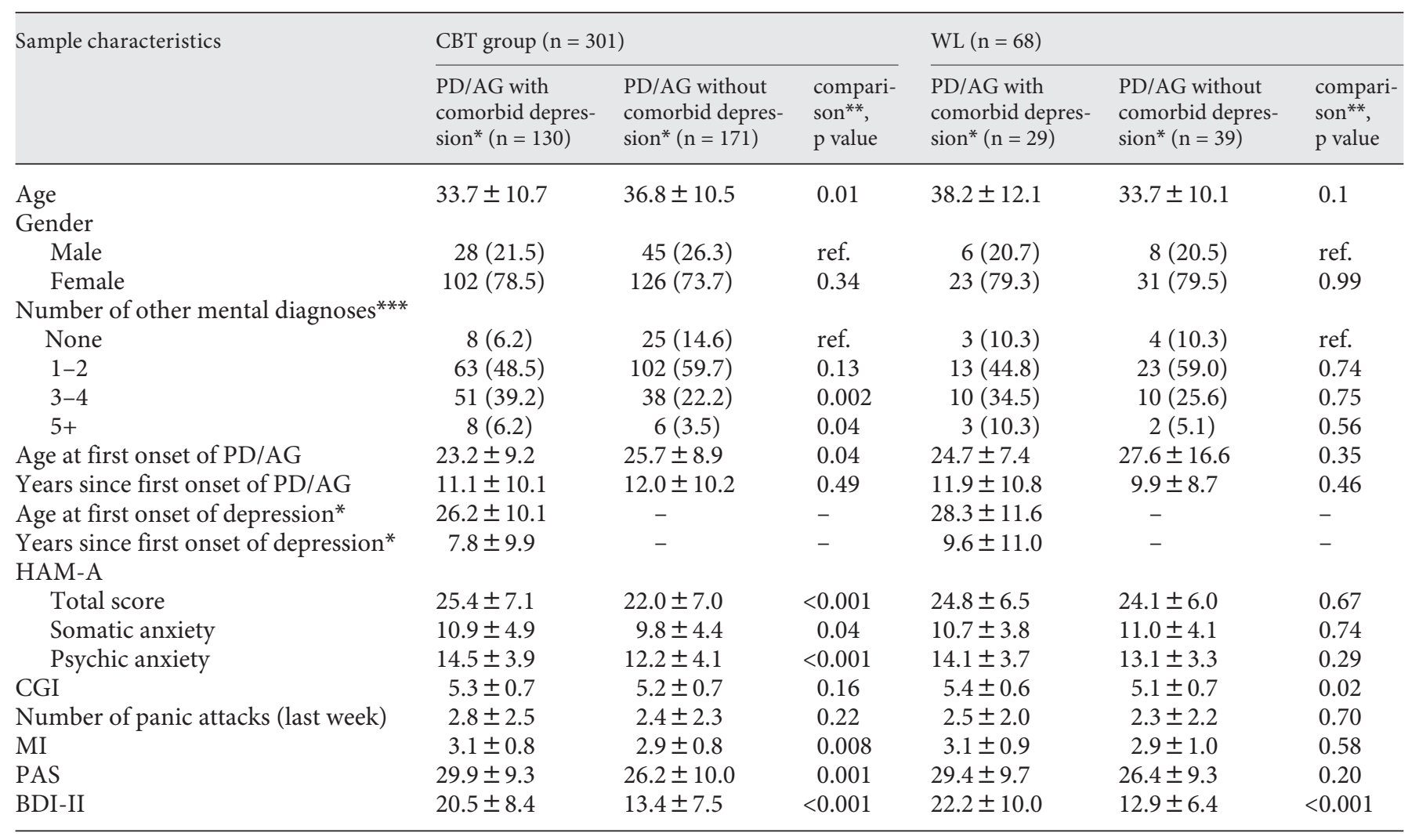

* 12-month prevalence of MDE and/or dysthymia at baseline; ${ }^{* *}$ with vs. without depression (mean difference/odds ratio calculated from linear/logistic regression); ${ }^{* *}$ additional to PD/AG and MDE/dysthymia; exclusion criteria were (a) comorbid psychotic or bipolar I disorder, (b) current alcohol dependence/current abuse or dependence for benzodiazepines and other psychoactive substances, (c) current suicidal intent, (d) borderline personality disorder. Results are presented as means \pm SD or numbers with percentages in parentheses.

the baseline BDI-II measure than those without depression. Except for number of panic attacks and the CGI they also scored higher on the dimensional baseline anxiety measures. The differences for the HAM-A remained even when excluding the item on depressive mood. In the WL, patients with comorbid depression revealed significantly higher CGI and BDI-II scores only. Out of the patients with comorbid MDE in the CBT group 33.3\% reported a single episode (WL 24.1\%), 51.4\% multiple episodes (WL 10.8\%) and $10.8 \%$ a chronic course of depression (WL 10.3\%).

\section{Effect of Depression Comorbidity (Categorical) on Anxiety Outcomes}

Model I (unadjusted) revealed considerable and significant post-treatment-BL and FU-6-BL symptom reductions in all anxiety outcome measures for CBT with no significant differences between patients with and without depression except for the somatic anxiety subscore of the HAM-A which decreased more in the noncomorbid depression group $(\mathrm{p}=0.04)$ (table 2 , upper part). At FU-6, ES increased in both groups, revealing no significant differences between those with and without depression, but again with the exception of the somatic anxiety subscore of the HAM-A $(\mathrm{p}=0.02)$. For the WL no significant posttreatment-BL symptom reductions (ES by outcome measure ranges from a low of 0.02 [BDI-II] to a high of -0.85 [CGI]) or differences in ES for patients with or without comorbid depression were observed.

Model II (adjusted; table 2, lower part) generally revealed similar findings; however there were significantly lower post-treatment-BL ES in the clinician-rated CGI $(\mathrm{p}=0.03)$, the HAM-A total score $(\mathrm{p}=0.008)$ and the HAM-A subscores (somatic anxiety $\mathrm{p}=0.001$; psychic 
Table 2. Anxiety and depression outcomes by baseline depression comorbidity (CBT group, $\mathrm{n}=301$ )

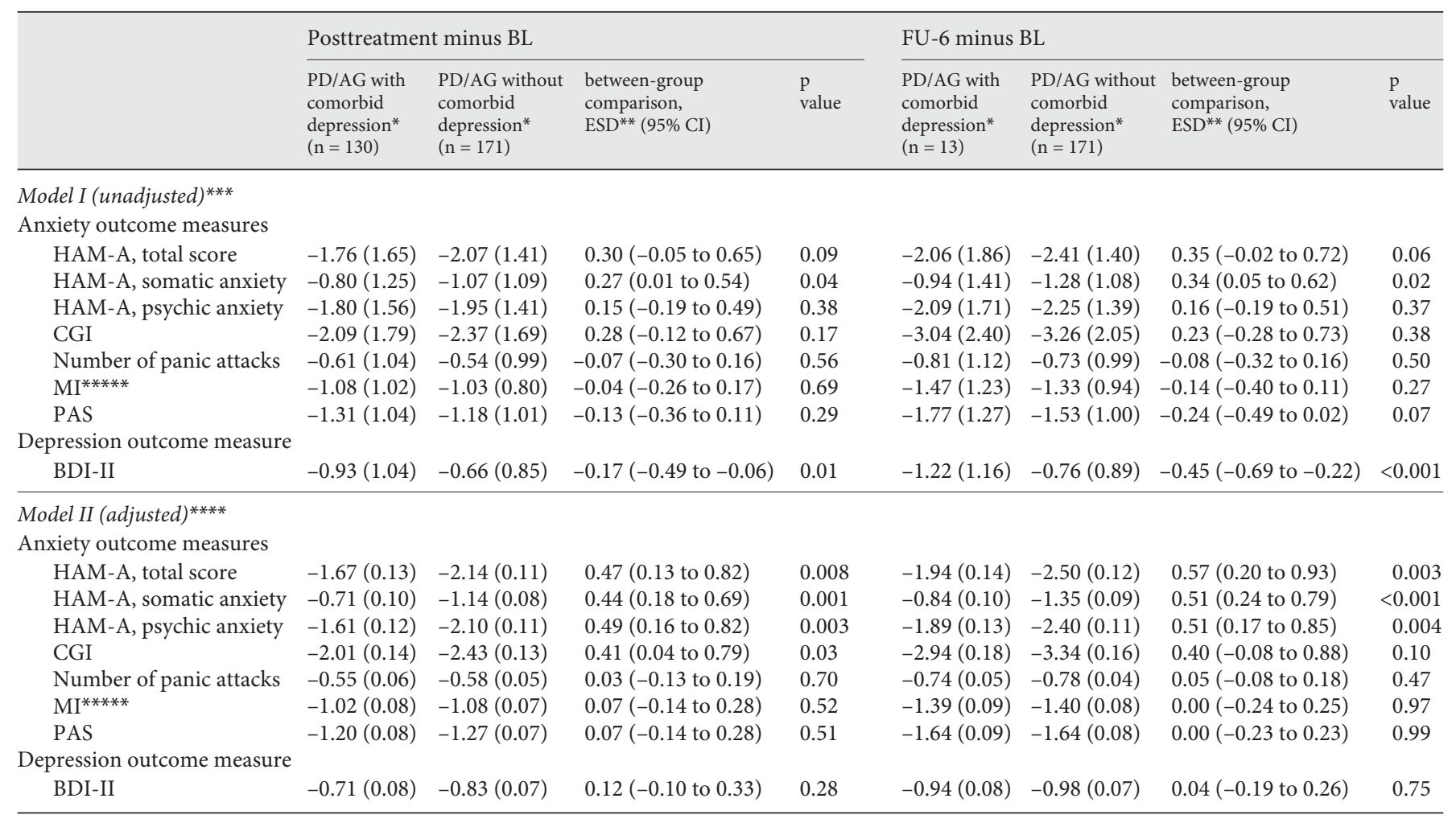

${ }^{*} \mathrm{MDE}$ or dysthymia, 12-month diagnosis at baseline; ** effect size difference calculated from linear regression, $>0$ means depression predicts worse outcome (shifts decrease in outcome toward 0); ${ }^{* *}$ ES (SD) unless indicated otherwise; ${ }^{* * * *}$ predicted values (evaluated at means of predictors with standard error of prediction); ${ }^{* * * *}$ with comorbid depression: $\mathrm{n}=120$; without comorbid depression: $\mathrm{n}=152$.

anxiety $\mathrm{p}=0.003$ ) among patients with comorbid depression. In the FU-6-BL comparison this difference was attenuated, remaining significant only for the HAMA (total score $\mathrm{p}=0.003$; somatic anxiety $\mathrm{p}<0.001$; psychic anxiety $\mathrm{p}=0.004)$.

\section{Effects of Baseline Depressive Symptomatology \\ (Dimensional) on Anxiety Outcomes}

Depression scores (as measured by the BDI-II) correlated moderately and differentially across the anxiety measures (Pearson $r=0.09-0.44$ ) indicating that different constructs (depression vs. anxiety) were measured. Figure 1 depicts the differential dimensional relationship of depressive symptoms with the outcome measures for the post-treatment-BL effects sizes and the FU-6-BL comparisons, supplemented by the overall regression means for patients with and without depression. No significant effects were observed in the WL. Following results refer to the active CBT condition.
Associations between Depressive Symptomatology

(Dimensional) and Anxiety Outcomes among

\section{CBT-Treated Patients}

Taking patients with and without depression together, model I (unadjusted, fig. 1a-e) revealed no significant effects of baseline depression severity on most anxiety outcomes, with two noteworthy exceptions: first, baseline BDI-II was significantly associated with poorer longterm outcome in the PAS total score, meaning that an increased depression score of 1 SD on the baseline BDI-II predicted lower FU-6-BL ES (effect size difference [ESD] $=0.17 ; 95 \%$ CI 0.04 to $0.30 ; p=0.011$ ). Second, for number of panic attacks a curvilinear association was observed between $\mathrm{BL}$ and post-treatment (squared term indicating more favorable ES with increasing BDI-II $=-0.13$; 95\% CI -0.22 to $0.03 ; \mathrm{p}=0.007)$. When adjusting for baseline severity, model II revealed that the BDI-II overall significantly predicted only the post-treatment-BL ES, on most anxiety outcome measures, with the exception of agora- 
phobic avoidance (MI). Higher baseline BDI-II scores were associated with lower post-treatment-BL ES in the HAM-A (total score: $\mathrm{ESD}=-0.40 ; 95 \% \mathrm{CI}-0.58$ to -0.21 ; $\mathrm{p}<0.001$; somatic anxiety: $\mathrm{ESD}=-0.27 ; 95 \% \mathrm{CI}-0.39$ to -0.15 ; $<<0.001$; psychic anxiety: ESD $=-0.40 ; 95 \% \mathrm{CI}$ -0.58 to $-0.23 ; \mathrm{p}<0.001)$, CGI $(\mathrm{ESD}=-0.22 ; 95 \% \mathrm{CI}$ -0.41 to $-0.03 ; \mathrm{p}=0.03$ ), number of panic attacks (ESD $=$ $-0.10 ; 95 \% \mathrm{CI}-0.18$ to $-0.01 ; \mathrm{p}=0.02)$ and the PAS $(\mathrm{ESD}=-0.14 ; 95 \% \mathrm{CI}-0.25$ to $-0.03 ; \mathrm{p}=0.02)$. At FU-6 though, associations remained significant only for the HAM-A (total score: $\mathrm{ESD}=-0.31 ; 95 \% \mathrm{CI}-0.51$ to -0.11 ; $\mathrm{p}=0.003$; somatic anxiety: $\mathrm{ESD}=-0.21 ; 95 \% \mathrm{CI}-0.34$ to $-0.08 ; \mathrm{p}<0.001 ;$ psychic anxiety: ESD $=-0.31 ; 95 \% \mathrm{CI}$ -0.49 to $-0.12 ; \mathrm{p}<0.001$ ).

Noteworthy, patients with extremely high BDI-II scores at BL seemed to have more panic attacks at posttreatment/FU- 6 than at BL. However, the low number of patients with very high BDI-II scores does not allow further testing or definite conclusions.

\section{Associations between Depressive Symptomatology}

(Dimensional) and Anxiety Outcomes as a Function of Depression Comorbidity (Categorical)

The slope and curvature of the curves on the dimensional relationship of depressive symptoms with the outcome measures (fig. 1) were not significantly different between patients with and without comorbid depression in both CBT and WL across any anxiety outcome measure. These results were observed despite indications that among patients with comorbid depression, those with the most severe depressive symptoms at BL had slightly lower ES at post-treatment. Effects appear to attenuate at FU-6 with one exception (number of panic attacks).

\section{Effects of CBT for PD/AG on Depressive}

Symptomatology (Dimensional) among Patients

with vs. without Comorbid Depression

ES in the CBT group reveal a substantial reduction of depressive scores during treatment that is maintained and even extended through the follow-up period. In both the unadjusted and adjusted models, patients with comorbid depression in the CBT group revealed greater improvement in BDI-II at post-treatment $(\mathrm{ESD}=-0.27 ; 95 \%$ CI -0.49 to $-0.06 ; \mathrm{p}=0.01)$ and FU-6 $(\mathrm{ESD}=-0.45 ; 95 \%$ CI -0.69 to $-0.22 ; \mathrm{p}<0.001$ ) (table 2). However, patients with comorbid depression still had significantly higher BDI-II scores at post-treatment than patients without comorbid depression (12.8 vs. 7.6; mean difference on unstandardized BDI-II $[\mathrm{MD}]=5.23 ; 95 \%$ CI 3.25 to $7.2 ; \mathrm{p}<$ 0.001 ) and FU-6 (10.3 vs. 6.6 ; $\mathrm{MD}=3.64 ; 95 \% \mathrm{CI} 1.67$ to
5.61; $\mathrm{p}<0.001)$. In contrast, the WL revealed no reduction of depressive symptoms.

\section{Effects of CBT for PD/AG on Depressive}

Symptomatology (Dimensional) Contingent on

Baseline Depression Severity

Dimensional reduction in BDI-II was most pronounced among those with the highest baseline BDI-II scores (fig. 1f). Higher BDI-II predicted overall higher ES on the BDI-II at post-treatment (model I: $\mathrm{ESD}=0.42 ; 95 \%$ CI 0.33 to $0.52 ; \mathrm{p}<0.001 /$ model II: $\mathrm{ESD}=0.42 ; 95 \% \mathrm{CI}$ 0.32 to $0.52 ; \mathrm{p}<0.001$ per standard deviation more on baseline BDI-II) and FU-6 (model I: ESD $=0.55$; 95\% CI 0.45 to $0.65 ; \mathrm{p}<0.001 /$ model II: $\mathrm{ESD}=0.54 ; 95 \%$ CI 0.44 to $0.65 ; \mathrm{p}<0.001)$. Slope and curvature of the curves did not differ between CBT patients with or without comorbid depression. However, overall curvilinear association indicating lower slope with higher baseline BDI-II severity was found at post-treatment (model I: ESD $=-0.08$; $95 \%$ CI -0.16 to $-0.01 ; \mathrm{p}=0.033 /$ model II: $\mathrm{ESD}=-0.08$; $95 \% \mathrm{CI}-0.16$ to $-0.01 ; \mathrm{p}=0.033)$, but not at FU-6.

\section{Discussion}

Prior research revealed inconsistent and inconclusive findings regarding (1) whether comorbid depression disorder (categorical) and the severity of depressive symptomatology (dimensional) affect post-treatment/followup anxiety outcomes of patients with PD/AG treated with $\mathrm{CBT}$ and (2) whether CBT for PD/AG also effectively reduces nontargeted depressive symptomatology. These clinically important questions were examined with data from a multicenter clinical CBT trial of 369 outpatients with a primary DSM-IV-TR diagnosis of PD/AG. CBT for $\mathrm{PD} / \mathrm{AG}$ was highly effective for the targeted primary anxiety outcomes measures irrespective of the presence of a comorbid depression disorder (categorical) or the severity of depressive symptomatology (dimensional). Further, CBT for PD/AG improved nontargeted depressive symptoms. Importantly, these results were found in a methodologically sufficient sample characterized by a large sample size and substantial statistical power to examine these questions; categorical and dimensional examination of the effect of depression and depressive symptomatology; inclusion of a broad range of anxiety outcome measures; use of a state-of-the-art CBT manual for PD/ AG that specifically focuses on anxiety without addressing depressive symptomatology, and the use of a control group without treatment. The present study did not use 
comorbid depression as an exclusion criterion and enrolled patients were treated across eight psychological and psychiatric treatment centers. As such, the characteristics of patients in this study can be considered typical for help seeking patients with PD/AG in outpatient settings.

As expected from epidemiological surveys, a substantial proportion of our patients with primary PD/AG [66, 67] suffered from a comorbid depressive disorder (MDE and/or dysthymia; 43\%). This rate was somewhat higher than those found in several other treatment studies of PD/ AG (13\% [40], 23\% [37], 21\% [43], 18\% [30]) or PD with or without AG (19\% [23], 12\% [27], 30\% [44]), but similar to the one reported by Starcevic et al. (48\%) [57]. Differences in rates of comorbid depression are likely due to differences in methodological factors. Patients with comorbid depressive disorder scored higher on the pretreatment MI, PAS and HAM-A than patients without depression. Whereas the increased HAM-A findings are not straightforward due to strong confounding with depression-relevant items (i.e. depressed mood, insomnia, poor concentration), these patterns of associations may suggest that comorbid depression exerts its effect indirectly on actual or perceived behavioral consequences rather than directly on symptom expression. Agoraphobic avoidance, as measured by the MI, typically involves a loss or reduction of meaningful reinforcers for the patient that are associated with restricted mobility and disability in daily activities. This is also supported by our finding of elevated baseline scores in the multidimensional PAS measure. Thus, we speculate that the higher MI and PAS scores at baseline likely represent perceived and real consequences of panic-associated avoidance behavior for the patient, whereas the increased HAM-A scores might more appropriately be interpreted as indicating higher overall illness severity [20].

Two main findings characterize the present study. First, overall comorbid depression does not significantly impact the short- and long-term (6-month) effect of CBT for PD/AG. Although slightly lower post-treatment effect sizes for clinician-rated primary outcome measures (CGI and HAM-A) were observed when adjusting for baseline anxiety severity, the effect was not substantiated by selfreport outcome measures. This effect was eliminated (CGI) or attenuated (HAM-A) at the FU-6. Dimensional analyses among cases with high baseline depressive symptomatology suggest the possibility of detrimental treatment response at post-treatment but not long-term (FU-6) effects on targeted primary anxiety outcomes. Second, CBT for PD/AG improved depressive symptoms in both, patients with and without diagnosable comorbid depression, irrespective of the severity of depression at baseline. This occurred without specifically targeting depression in therapy.

These main findings have important implications for clinical care. CBT for PD/AG is sometimes assumed to be effective primarily for monosymptomatic patients with mild illness severity. Our findings provide evidence that overall CBT for PD/AG is effective irrespective of comorbid depression or severity of depressive symptomatology. In clinical routine, many clinicians tend to modify their therapeutic strategy by addressing depressive symptoms when deemed necessary. Practitioners thereby deviate from established state-of-the-art manuals for PD/AG. Although it remains an empirical question as to whether these findings could have otherwise been further bolstered, our results strongly suggest that retaining a consistent focus on the primary anxiety diagnosis does not negatively affect the short- and long-term anxiety outcomes and also reduces depressive symptomatology. CBT is a first-line treatment for PD/AG, can be administered alone, and needs to be further investigated given the unclear role of psychopharmacotherapy $[58,59]$.

\section{Effects of Depression/Depressive Symptomatology on} Anxiety Outcomes

Although the results suggest that depression does not negatively affect primary anxiety outcome it is importantly to note that the number of PD/AG patients with extremely elevated depression scores was relatively limited. We cannot exclude the possibility of different treatment needs among the few $\mathrm{PD} / \mathrm{AG}$ patients with the most severe depression. Findings that primary PD/AG patients with the most severe baseline depressive symptoms had somewhat attenuated responses on some measures - at least in the post-treatment-BL period - raise the question of whether this subgroup may require additional interventions that specifically target depression [60].

Our findings also highlight the importance of examining treatment effects and follow-up outcomes separately by outcome measure. Patients with depression comorbidity, compared to those without, revealed no differences in effect sizes on any self-report questionnaires. However, depression comorbidity was associated with lower treatment response on clinician-rated measures at least when the analyses were adjusted for baseline levels of the respective outcome. It is likely that clinicians put a greater weight on the depressive symptomatology and its consequences, while the patient does not seem to take this equally into account. As differential depression effects of 
clinician ratings were attenuated at follow-up, we interpret our findings overall as reflecting evidence that $\mathrm{PD} /$ AG patients with comorbid depression benefit similarly from treatment as patients without depression. This conclusion is in line with interpretations from studies that found positive treatment effects are retained or even enhanced in the follow-up period [21-26, 28, 30, 31].

\section{Effects of CBT for PD/AG on Depressive}

Symptomatology

Concerning the question of whether $\mathrm{CBT}$ for $\mathrm{PD} / \mathrm{AG}$ also effectively reduces the severity of nontargeted cooccurring depressive symptoms without using explicit antidepressive strategies, we found remarkable and significant effect sizes. Even for patients with comorbid depression at BL the mean BDI-II values at post-treatment and FU-6 were within the range of no/minimal depression (0-13) according to the cut-offs of the BDI-II [54]. Positive effects of CBT for PD/AG on depressive symptomatology were observed in those with and those without comorbid depressive disorder and continued in the follow-up period. Overall, these results are comparable to prior findings [23, 30, 43, 44], except for McLean et al. [21] and Woody et al. [45], who excluded patients with any other comorbid axis I disorder than PD, AG or depression. This discrepancy of findings suggests possible interactions between several other types of comorbidity.

The question why CBT for PD/AG also effectively reduces depression remains unclear. The lack of any improvement in the WL shows that it is not due to spontaneous remission over time. So what could be the underlying mechanisms of action in CBT explaining this remarkable effect? One possible explanation is that CBT simultaneously functions as a type of behavioral activation (exposure in situ and anxiety exercises with homework assignments), which in itself is a reasonable treatment for depression $[61,62]$. Patients may also enhance their self-efficacy expectations or self-esteem due to the experiences of getting the exposure exercises done within the treatment for PD/AG. Detailed analysis of these issues is clearly needed [63].

Findings must be viewed in the light of several limitations. First, this study is based on post-hoc analyses of a clinical randomized trial that examined two variants of CBT for PD/AG, thus patients were not randomized based on the comorbid diagnostic status of depression. Second, possible differences in results for different types of comorbid major depression (single episode, recurrent, chronic, melancholic features) or dysthymia [64] were not separately considered in this paper. Third, other comorbid dis- orders (like other anxiety disorders, axis-II disorders) were not considered in the present analyses but may also have affected treatment response on CBT for PD/AG. Fourth, patients were treated within academic centers according to a manual-based CBT. Further, they had to agree to discontinue all psychopharmacological medication and to undergo a washout period prior to baseline. Exclusion criteria were explicitly bipolar affective disorder and suicidality. These conditions may differ from less controlled natural therapy settings in routine care, thus limiting the generalizability of our results to other settings and in particular to severe and complicated forms of depression. And, finally, we did not differentiate the two variants of exposure (in situ exposure with vs. without therapist during exposure exercises) in the current study and further differentiated analyses on a possible moderator function of treatment condition on the association of comorbid depression with treatment outcomes are warranted.

To conclude, comorbid depression, defined as meeting DSM-IV-TR criteria for major depression, dysthymia or both, overall does not significantly impact the short- and long-term efficacy of an exposure-based CBT for PD/AG patients. Similarly, the level of depressive symptomatology does not play a meaningful role for the targeted anxiety outcome. This held true across various established anxiety outcome measures. These results are encouraging, for they provide evidence that depressive patients can benefit from CBT for PD/AG. Indeed, the CBT treatment used in this study was highly effective for PD/AG and cooccurring depressive symptomatology alike. Examination of how and why CBT or its components in particular contributes to the reduction in depressive symptomatology is highly warranted to improve intervention strategies.

\section{Acknowledgments}

\section{Funding/Support}

This work is part of the German multicenter trial 'Mechanisms of Action in CBT (MAC)'. The MAC study is funded by the German Federal Ministry of Education and Research (BMBF; project no. 01GV0615) as part of the BMBF Psychotherapy Research Funding Initiative.

\section{Centers}

Principal investigators (PI) with respective areas of responsibility in the MAC study are V. Arolt (Münster: overall MAC program coordination), H.-U. Wittchen (Dresden: PI for the randomized clinical trial and manual development), A. Hamm (Greifswald: PI for psychophysiology), A.L. Gerlach (Münster: PI 
for psychophysiology and panic subtypes), A. Ströhle (Berlin: PI for experimental pharmacology), T. Kircher (Marburg: PI for functional neuroimaging), and J. Deckert (Würzburg: PI for genetics). Additional site directors in the RTC component of the program are G.W. Alpers (Würzburg), T. Fydrich and L. Fehm (Berlin-Adlershof), and T. Lang (Bremen).

\section{Data Access and Responsibility}

All principle investigators take responsibility for the integrity of the respective study data and their components. All authors and co-authors had full access to all study data. Data analyses and manuscript preparation were completed by the authors and coauthors of this article, who take responsibility for its accuracy and content.

\section{Acknowledgements and Staff Members by Site}

Greifswald (coordinating site for psychophysiology): Christiane Melzig, Jan Richter, Susan Richter, Matthias von Rad; Berlin-Charite (coordinating center for experimental pharmacology): Harald Bruhn, Anja Siegmund, Meline Stoy, Andre Wittmann; Berlin-Adlershof: Irene Schulz; Münster (overall MAC program coordination, genetics and functional neuroimaging): Andreas Behnken, Katharina Domschke, Adrianna Ewert, Carsten Konrad, Bettina Pfleiderer, Peter Zwanzger; Münster (coordinating site for psychophysiology and subtyping): Judith Eidecker, Swantje Koller, Fred Rist, Anna Vossbeck-Elsebusch; Marburg/Aachen (coordinating center for functional neuroimaging): Barbara Drüke, Sonja Eskens, Thomas Forkmann, Siegfried Gauggel, Susan Gruber, Andreas Jansen, Thilo Kellermann, Isabelle Reinhardt, Nina Vercamer-Fabri; Dresden (coordinating site for data collection, analysis, and the RCT): Franziska Einsle, Christine Fröhlich, Andrew T. Gloster, Christina Hauke, Simone Heinze, Michael Höfler, Ulrike Lueken, Peter Neudeck, Stephanie Preiss, Dorte Westphal; Würzburg Psychiatry Department (coordinating center for genetics): Andreas Reif; Würzburg Psychology Department: Julia Dürner, Hedwig Eisenbarth, Antje B.M. Gerdes, Harald Krebs, Paul Pauli, Silvia Schad, Nina Steinhäuser; Bremen: Veronika Bamann, Sylvia Helbig-Lang, Anne Kordt, Pia Ley, Franz Petermann, Eva-Maria Schröder. Additional support was provided by the coordinating center for clinical studies in Dresden (KKS Dresden): Xina Grählert and Marko Käppler.

The RTC project was approved by the Ethics Committee of the Medical Faculty of the Technische Universität Dresden (EK 164082006). The neuroimaging components were approved by the Ethics Committee of the Medical Faculty of the RheinischWestfälische Hochschule University Aachen (EK 073/07). The experimental pharmacology study was approved by the Ethics Committee of the state of Berlin (EudraCT: 2006-00-4860-29).

The study was registered with the ISRCTN: ISRCTN80046034.

\section{Disclosure Statement}

Angela Emmrich, Katja Beesdo-Baum, Susanne Knappe, Andrew Gloster, Michael Höfler, Alexander Gerlach, Tilo Kircher, Thomas Lang, and Jan Richter declare to have no conflicts of interest.

Volker Arolt is member of advisory boards and/or gave presentations for the following companies: Astra-Zeneca, Janssen-Organon, Lilly, Lundbeck, Servier, Pfizer, and Wyeth. He chairs the committee for the 'Wyeth Research Award Depression and Anxiety', now the DGPPN/Pfizer 'Clinical Neuroscience Award'.

Jürgen Deckert received in the past 3 years honoraria by Janssen, Bristol Myers-Squibb, Wyeth, Lundbeck, Astra-Zeneca and Pfizer and grant support by Medice, Lundbeck and AstraZeneca.

Alfons Hamm received in the past 3 years research grants by the German Research Foundation, the National Institute of Mental Health, and the Federal Ministry of Education and Research.

Andreas Ströhle received in the past 3 years research funding from the German Federal Ministry of Education and Research, the European Commission (FP6) and Lundbeck, and speaking honoraria from AstraZeneca, Boehringer Ingelheim, BristolMyers Squibb, Eli Lilly \& Co, Lundbeck, Pfizer, Wyeth and UCB. Educational grants were given by the Stifterverband für die Deutsche Wissenschaft, the Berlin Brandenburgische Akademie der Wissenschaften, the Boehringer Ingelheim Fonds and the Eli Lilly International Foundation.

Peter Zwanzger received in the past 3 years research funding from the German Federal Ministry of Education and Research, the German Research Foundation, the Interdisziplinäres Zentrum für Klinische Forschung Münster and Astra Zeneca, and speaking honoraria from Pfizer, Servier, Lilly, Astra Zeneca, Bristol Myers Squibb. He was a consultant for Pfizer.

Hans-Ulrich Wittchen received in the past 3 years research funding from the German Federal Ministry of Education and Research, Essex Pharma, Sanofi, Pfizer, Organon, Servier and Novartis and speaking honoraria or travel reimbursements from Essex Pharma, Sanofi, Pfizer, Organon, Servier and Novartis. He is currently or has in the past 3 years been a member of advisory boards of several pharmaceutical companies.

These affiliations have no relevance to the work covered in this paper.

\section{References}

1 Barlow DH, Gorman JM, Shear MK, Woods SW: Cognitive-behavioral therapy, imipramine, or their combination for panic disorder - a randomized controlled trial. JAMA 2000;283:2529-2536.

2 Clum GA, Clum GA, Surls R: A Metaanalysis of treatments for panic disorder. J Consult Clin Psychol 1993;61:317-326.
3 Gloster AT, Wittchen H-U, Einsle F, Lang T, Helbig-Lang S, Fydrich T, Fehm L, Hamm AO, Richter J, Alpers GW, Gerlach AL, Stroehle A, Kircher T, Deckert J, Zwanzger P, Hoefler M, Arolt V: Psychological treatment for panic disorder with agoraphobia: a randomized controlled trial to examine the role of therapist-guided exposure in situ in CBT. J Consult Clin Psychol 2011;79:406-420. 
4 McHugh RK, Smits JAJ, Otto MW: Empirically supported treatments for panic disorder. Psychiatr Clin North Am 2009;32:593610.

5 Arch JJ, Craske MG: First-line treatment: a critical appraisal of cognitive behavioral therapy developments and alternatives. Psychiatr Clin North Am 2009;32:525-548.

6 Wittchen HU, Beesdo K, Bittner A, Goodwin RD: Depressive episodes - evidence for a causal role of primary anxiety disorders? Eur Psychiatry 2003;18:384-393.

7 Beesdo K, Pine DS, Lieb R, Wittchen HU: Incidence and risk patterns of anxiety and depressive disorders and categorization of generalized anxiety disorder. Arch Gen Psychiatry 2010;67:47-57.

8 Bittner A, Goodwin RD, Wittchen HU, Beesdo K, Hofler M, Lieb R: What characteristics of primary anxiety disorders predict subsequent major depressive disorder? J Clin Psychiatry 2004;65:618-626.

9 Beesdo K, Bittner A, Pine DS, Stein MB, Hofler M, Lieb R, Wittchen HU: Incidence of social anxiety disorder and the consistent risk for secondary depression in the first three decades of life. Arch Gen Psychiatry 2007;64:903-912.

10 Pine DS, Cohen P, Gurley D, Brook J, Ma YJ: The risk for early-adulthood anxiety and depressive disorders in adolescents with anxiety and depressive disorders. Arch Gen Psychiatry 1998;55:56-64.

11 Wittchen HU: Natural course and spontaneous remission of untreated anxiety disorders: results of the Munich Follow-up Study (MFS); in Hand I, Wittchen HU (eds): Panic and Phobias II. Berlin, Springer, 1988, pp 3-17.

12 Goodwin RD: Anxiety disorders and the onset of depression among adults in the community. Psychol Med 2002;32:1121-1124.

13 Wittchen HU, Essau CA: Comorbidity of anxiety disorders and depression: does ist af fect course and outcome? Psychiatr Psychobiol 1989;4:315-324.

14 Wittchen HU, Essau CA, Krieg JC: Anxiety disorders - similarities and differences of comorbidity in treated and untreated groups. Br J Psychiatry 1991;159:23-33.

15 Roy-Byrne PP, Stang P, Wittchen HU, Ustun B, Walters EE, Kessler RC: Lifetime panicdepression comorbidity in the National Comorbidity Survey - association with symptoms, impairment, course and help-seeking. Br J Psychiatry 2000;176:229-235.

16 Goodwin RD, Faravelli C, Rosi S, Cosci F, Truglia E, de Graaf R, Wittchen HU: The epidemiology of panic disorder and agoraphobia in Europe. Eur Neuropsychopharmacol 2005; 15:435-443.

17 Goodwin RD, Olfson M: Treatment of panic attack and risk of major depressive disorder in the community. Am J Psychiatry 2001; 158:1146-1148.
18 Johnson MR, Lydiard RB: Comorbidity of major depression and panic disorder. J Clin Psychol 1998;54:201-210.

19 Kessler RC, Stang PE, Wittchen HU, Ustun TB, Roy-Burne PP, Walters EE: Lifetime panic-depression comorbidity in the National Comorbidity Survey. Arch Gen Psychiatry 1998;55:801-808.

20 Baldwin DS: Depression and panic: comorbidity. Eur Psychiatry 1998;13:65S-70S.

21 McLean PD, Woody S, Taylor S, Koch WJ: Comorbid panic disorder and major depression: implications for cognitive-behavioral therapy. J Consult Clin Psychol 1998;66:240-247.

22 Rief W, Trenkamp S, Auer C, Fichter MM: Cognitive behavior therapy in panic disorder and comorbid major depression - a naturalistic study. Psychother Psychosom 2000; 69:70-78.

23 Allen LB, White KS, Barlow DH, Shear MK, Gorman JM, Woods SW: Cognitive-behavior therapy (CBT) for panic disorder: relationship of anxiety and depression comorbidity with treatment outcome. J Psychopathol Behav Assess 2010;32:185-192.

24 Laberge B, Gauthier JG, Cote G, Plamondon J, Cormier HJ: Cognitive-behavioral therapy of panic disorder with secondary major depression - a preliminary investigation. J Consult Clin Psychol 1993;61:1028-1037.

25 Maddock RJ, Blacker KH: Response to treatment in panic disorder with associated depression. Psychopathology 1991;24:1-6.

26 Albus M, Scheibe G, Scherer J: Panic disorder with or without concomitant depression 5 years after treatment: a prospective followup. J Affect Disord 1995;34:109-115.

27 Davis L, Barlow DH, Smith L: Comorbidity and the treatment of principal anxiety disorders in a naturalistic sample. Behav Ther 2010;41:296-305.

28 Rief W, Auer C, Wambach K, Fichter MM: Treatment of patients with panic disorder and comorbid depression. Z Klin Psychol Psychother 2003;32:210-218.

29 Dow MGT, Kenardy JA, Johnston DW, Newman MG, Taylor CB, Thomson A: Prognostic indices with brief and standard CBT for panic disorder. I. Predictors of outcome. Psychol Med 2007;37:1493-1502.

30 Tsao JCI, Mystkowski JL, Zucker BG, Craske MG: Effects of cognitive-behavioral therapy for panic disorder on comorbid conditions: replication and extension. Behav Ther 2002; 33:493-509.

31 Basoglu M, Marks IM, Swinson RP, Noshirvani H, Osullivan G, Kuch K: Pretreatment predictors of treatment outcome in panic disorder and agoraphobia treated with Alprazolam and exposure. J Affect Disord 1994;30:123-132.

32 Keller MB, Lavori PW, Goldenberg IM, Baker LA, Pollack MH, Sachs GS, Rosenbaum JF, Deltito JA, Leon A, Shear K, Klerman GL: Influence of depression on the treatment of panic disorder with imipramine, alprazolam and placebo. J Affect Disord 1993;28:27-38.
33 Bruce SE, Yonkers KA, Otto MW, Eisen JL, Weisberg RB, Pagano M, Shea MT, Keller MB: Influence of psychiatric comorbidity on recovery and recurrence in generalized anxiety disorder, social phobia, and panic disorder: a 12-year prospective study. Am J Psychiatry 2005; 162:1179-1187.

34 Fava GA, Rafanelli C, Grandi S, Conti S, Ruini C, Mangelli L, Belluardo P: Long-term outcome of panic disorder with agoraphobia treated by exposure. Psychol Med 2001;31: 891-898.

35 Noyes R, Clancy J, Woodman C, Holt CS, Suelzer M, Christiansen J, Anderson DJ: Environmental-factors related to the outcome of panic disorder - a 7-year follow-up study. J Nerv Ment Dis 1993;181:529-538.

36 Scheibe G, Albus M: Predictors of outcome in panic disorder: a 5-year prospective follow-up study. J Affect Disord 1996;41:111116.

37 Steketee G, Chambless DL, Tran GQ: Effects of axis I and II comorbidity on behavior therapy outcome for obsessive-compulsive disorder and agoraphobia. Compr Psychiatry 2001;42:76-86

38 van Balkom A, van Boeijen CA, Boeke AJP, van Oppen P, Kempe PT, van Dyck R: Comorbid depression, but not comorbid anxiety disorders, predicts poor outcome in anxiety disorders. Depress Anxiety 2008;25: 408-415.

39 van Valkenburg C, Akiskal HS, Puzantian V, Rosenthal T: Anxious depressions clinical family history and naturalistic outcome comparisons with panic and major depressive disorder. J Affect Disord 1984;6:67-82.

40 Brown TA, Antony MM, Barlow DH: Diagnostic comorbidity in panic disorder: effect on treatment outcome and course of comorbid diagnoses following treatment. J Consult Clin Psychol 1995;63:408-418.

41 Pollack MH, Otto MW, Tesar GE, Cohen LS, Meltzerbrody S, Rosenbaum JF: Long-term outcome after acute treatment with alprazolam or clonazepram for panic disorder. J Clin Psychopharmacol 1993;13:257-263.

42 Keijsers GPJ, Hoogduin CAL, Schaap C: Prognostic factors in the behavioral treatment of panic disorder with and without agoraphobia. Behav Ther 1994;25:689-708.

43 Tsao JCI, Lewin MR, Craske MG: The effects of cognitive-behavior therapy for panic disorder on comorbid conditions. J Anxiety Disord 1998;12:357-371.

44 Tsao JCI, Mystkowski JL, Zucker BG, Craske MG: Impact of cognitive-behavioral therapy for panic disorder on comorbidity: a controlled investigation. Behav Res Ther 2005; 43:959-970.

45 Woody S, McLean PD, Taylor S, Koch WJ Treatment of major depression in the context of panic disorder. J Affect Disord 1999;53: 163-174. 
46 Gloster AT, Wittchen HU, Einsle F, Hofler M, Lang T, Helbig-Lang S, Fydrich T, Fehm L, Hamm AO, Richter J, Alpers GW, Gerlach AL, Strohle A, Kircher T, Deckert J, Zwanzger P, Arolt V: Mechanism of action in CBT (MAC): methods of a multi-center randomized controlled trial in 369 patients with panic disorder and agoraphobia. Eur Arch Psych Clin Neurosci 2009;259(suppl 2):S155S166.

47 Gloster AT, Wittchen H-U, Einsle F, Lang T, Helbig-Lang S, Fydrich T, Fehm L, Hamm AO, Richter J, Alpers GW, Gerlach AL, Strohle A, Kircher T, Deckert J, Zwanzger P, Hofler M, Arolt V: Correction to Gloster et al. J Consult Clin Psychol 2011;79:652.

48 Wittchen HU, Pfister H: DIA-X-Interviews: Manual für Screening-Verfahren und Interview; Interviewheft Längsschnittuntersuchung (DIA-X-Lifetime); Ergänzungsheft (DIA-X-Lifetime); Interviewheft Querschnittuntersuchung (DIA-X-12-Monate); Ergänzungsheft (DIA-X-12-Monate); PCProgramm zur Durchführung des Interwiews (Längs- und Querschnittuntersuchung); Auswertungsprogramm. Frankfurt, Swets \& Zeitlinger, 1997.

49 Shear MK, Vander Bilt J, Rucci P, Endicott J, Lydiard B, Otto MW, Pollack MH, Chandler L, Williams J, Ali A, Frank DM: Reliability and validity of a Structured Interview Guide for the Hamilton Anxiety Rating Scale (SIGH-A). Depress Anxiety 2001;13:166178.

50 Hamilton M: The assessment of anxiety states by rating. Br J Med Psychol 1959;32: $50-55$.
51 Guy W: Clinical global impression; in Guy W (ed): EC-DEU assessment manual for psychopharmacology, revised. Rockville, National Institute of Mental Health, 1976, pp 217-222.

52 Bandelow B: Panic and Agoraphobia Scale (PAS). Ashland, Hogrefe \& Huber Publishers, 1999.

53 Chambless DL, Caputo GC, Jasin SE, Gracely EJ, Williams C: The mobility inventory for agoraphobia. Behav Res Ther 1985;23:35-44.

54 Hautzinger M, Keller F, Kühner C: Beck Depressions-Inventar (BDI-II), revision. Frankfurt/Main, Harcourt Test Services, 2006.

55 Lang T, Helbig-Lang S, Westphal D, Gloster AT, Wittchen HU: Expositionsbasierte Therapie der Panikstörung mit Agoraphobie. Göttingen, Hogrefe, 2011.

56 Härdle W: Applied Nonparametric Regression (Biometric Society Monographs No. 19). Cambridge, Cambridge University Press, 1990.

57 Starcevic V, Uhlenhuth EH, Kellner R, Pathak D: Patterns of comorbidity in panic disorder and agoraphobia. Psychiatry Res 1992;42:171-183.

58 Fava GA: Statistical alchemy for drug treatment of generalized anxiety disorder: a commentary on the meta-analysis by Baldwin et al. [BMJ 2011;342:d1199]. Psychother Psychosom 2011;80:261-263.

59 Pigott HE, Leventhal AM, Alter GS, Boren JJ: Efficacy and effectiveness of antidepressants: current status of research. Psychother Psychosom 2010;79:267-279.
60 Craske MG, Farchione TJ, Allen LB, Barrios V, Stoyanova M, Rose R: Cognitive behavioral therapy for panic disorder and comorbidity: more of the same or less of more? Behav Res Ther 2007;45:1095-1109.

61 Hopko DR, Lejuez CW, Ruggiero KJ, Eifert $\mathrm{GH}$ : Contemporary behavioral activation treatments for depression: procedures, principles, and progress. Clin Psychol Rev 2003; 23:699-717.

62 Jacobson NS, Martell CR, Dimidjian S: Behavioral activation treatment for depression: returning to contextual roots. Clin Psychol Sci Pract 2001;8:255-270.

63 Fava GA, Grandi S, Canestrari R, Grasso P, Pesarin F: Mechanisms of change of panic attacks with exposure treatment of agoraphobia. J Affect Disord 1991;22:65-71.

64 Chambless DL, Renneberg B, Gracely EJ, Goldstein AJ, Fydrich T: Axis I and II comorbidity in agoraphobia: prediction of psychotherapy outcome in a clinical setting. Psychother Res 2000;10:279-295.

65 Lang T, Helbig-Lang S: Exposure in vivo with and without presence of a therapist Does it matter?; in Neudeck P, Wittchen HU (eds): Exposure Therapy: Rethinking the Model - Refining the Method. New York, Springer, in press.

66 Wittchen HU, Nocon A, Beesdo K, Pine DS, Hofler M, Lieb R, Gloster AT: Agoraphobia and panic. Psychother Psychosom 2008;77: 147-157.

67 Wittchen HU, Gloster AT, Beesdo-Baum K, Fava GA, Craske MG: Agoraphobia: a review of the diagnostic classificatory position and criteria. Depress Anxiety 2010;27:113-133. 